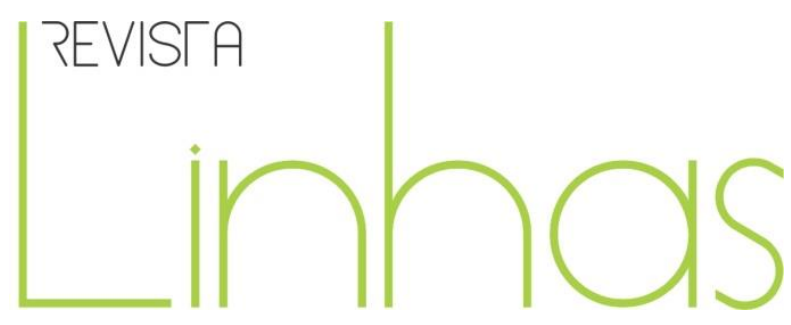

\title{
Avaliação da aprendizagem na educação infantil: um estudo exploratório em 125 municípios brasileiros
}

\section{Resumo}

Este artigo visa socializar parte dos resultados advindos da pesquisa realizada por solicitação da Coordenação Geral da Educação Infantil (COEDI)/Secretaria de Educação Básica do Ministério da Educação (SEB/MEC), com apoio da UNESCO (Organização das Nações Unidas para a Educação, a Ciência e a Cultura), que buscou verificar se as orientações federais relativas à avaliação da aprendizagem das crianças expressas na legislação vigente e documentos normativos da área são compreendidas, implementadas e utilizadas pelas redes municipais de educação infantil e suficientes para garantir que a avaliação ocorra de forma alinhada aos fins e objetivos da educação infantil. Para tal, foram mapeadas iniciativas municipais de avaliação da aprendizagem das crianças matriculadas na educação infantil e no primeiro ano do ensino fundamental de 125 municípios brasileiros, distribuídos em 22 estados, com vistas a melhor compreender no que consistem essas iniciativas e, assim, fomentar o debate na área. Os dados analisados, provenientes de um survey respondido por mais de 200 conselheiros e/ou dirigentes municipais de educação, e também da análise de 23 instrumentos avaliativos, apontam que há ainda um longo caminho a ser percorrido na construção e consolidação de uma avaliação de aprendizagem na educação infantil na perspectiva da garantia dos direitos fundamentais das crianças.

Palavras-chave: Educação Infantil. Avaliação da Aprendizagem. Avaliação de Crianças. Educação de Crianças. Avaliação Educacional. Aprendizagem.

\section{Para citar este artigo:}

RIBEIRO, Bruna. Avaliação da aprendizagem na educação infantil: um estudo exploratório em 125 municípios brasileiros. Revista Linhas. Florianópolis, v. 19, n. 40, p. 218-245, maio/ago. 2018. 


\title{
Evaluation of learning in children education: an exploratory study in 125 brazilian municipalities
}

\begin{abstract}
This article aims to socialize part of the results of research carried out at the request of the General Coordination of Early Childhood Education (COEDI) / Secretariat of Basic Education of the Ministry of Education (SEB / MEC), with support from UNESCO (United Nations Educational, Science and Culture), which sought to verify that the federal guidelines on evaluation of children's learning expressed in the current legislation and normative documents of the area are understood, implemented and used by the municipal nursery schools and sufficient to ensure that the evaluation occurs in line with the aims and objectives of early childhood education. To this end, municipal initiatives to assess the learning of children enrolled in early childhood education and in the first year of elementary education in 125 Brazilian municipalities, distributed in 22 states, were mapped in order to better understand what these initiatives consist of, and thus foster debate in area. The data analyzed, from a survey that was answered by more than 200 counselors and / or municipal education managers, and also from the analysis of 23 evaluation instruments, point out that there is still a long way to go in building and consolidating a learning assessment in early childhood education with a view to ensuring the fundamental rights of children.
\end{abstract}

Keywords: Early Childhood Education. Evaluation of Learning. Evaluation of Children. Education of Children. Educational Evaluation. Learning. 


\section{Introdução e justificativa}

A Educação Infantil se constitui como direito de todas as crianças desde o nascimento e dever do Estado, conforme preconiza a Constituição Federal (BRASIL, 1988), sendo incluída nos sistemas de ensino como primeira etapa da Educação Básica pela Lei de Diretrizes e Bases da Educação Nacional, de 1996.

Não obstante esse estatuto legal, o Sistema Nacional de Avaliação da Educação Básica/Saeb1, implantado no Brasil desde o início da década de 1990, não contemplava iniciativas relacionadas à avaliação da/na ${ }^{2}$ educação infantil, conforme evidenciado por Sousa (2014). Somente nos últimos anos acompanhamos o que alguns autores, como Rosemberg (2013), situaram como a emergência de um "novo problema social” no campo da educação infantil, no que diz respeito à temática da avaliação.

A aprovação do Plano Nacional de Educação ${ }^{3}$ (2014-2024), em junho de 2014, lança luz ao debate e desafia especialistas, legisladores e gestores públicos a construírem uma política nacional de avaliação da/na educação infantil que supere a "fase de uma desconfiança generalizada sobre todas as formas de avaliação, que ainda perdura no Brasil”, conforme evidencia Campos (2016, p. 43), mas que também esteja alinhada aos fins, objetivos e finalidades desta etapa, como defende Didonet (2011).

Nesse cenário em que a temática da avaliação em educação infantil adquire o status de "problema social” (ROSEMBERG, 2013) e diferentes iniciativas estão em curso, um breve levantamento bibliográfico sobre a temática evidencia, todavia, escassez de materiais acadêmicos e da literatura em geral que abordem a questão da avaliação sob a perspectiva específica da educação infantil e também a sua quase invisibilidade quando se trata de estudos mais amplos que realizam um balanço sobre avaliação na Educação

\footnotetext{
${ }^{1}$ SAEB substituído pela SINAEB (Sistema Nacional de Avaliação da Educação Básica), em maio de 2016 e revogado em agosto do mesmo ano pela Portaria 981, publicada no Diário Oficial da União de 26/08/2016 ( ( $^{\circ}$ 165, Seção 1, pág. 16).

2 O termo avaliação "na" e "da" educação infantil é utilizado segundo conceituação proposta por Didonet (2011).

${ }^{3}$ O PNE prevê como estratégia para a expansão da oferta com qualidade: avaliação a ser realizada a cada 2 (dois) anos, com base em parâmetros nacionais de qualidade, a fim de aferir a infraestrutura física, o quadro de pessoal, as condições de gestão, os recursos pedagógicos, a situação de acessibilidade, entre outros indicadores relevantes" (BRASIL, Lei 13.005/ 2014, Meta 1, item 1.6).
} 
Básica, como demonstrado nas pesquisas de Barreto e colaboradores (2001) ${ }^{4}$, Poltronieri e Calderón (2012) e Rosemberg (2013).

Essa lacuna nas produções sobre avaliação na Educação Básica parece refletir o lugar que a educação infantil ocupou historicamente em relação às demais etapas educacionais, nos sugerindo também que parte importante do processo de fortalecimento da identidade da educação infantil como primeira etapa da educação básica pressupõe a construção de um corpus composto de referenciais teóricos, estudos, pesquisas sobre estado da arte e mapeamento de experiências em curso nacional e internacionalmente.

Algumas iniciativas foram feitas nesse sentido, com especial destaque para Ciasca e Mendes (2009), Moro (2013), Neves e Moro (2013), Moro e Sousa (2014), Ribeiro (2010; 2016) e Sousa e Pimenta (2016).

No entanto, a maior parte dos estudos e pesquisas que buscaram mapear as produções sobre avaliação especificamente no âmbito da educação infantil serve para constatar a reduzida existência de estudos sobre a temática e a pouca atenção dada ao tema no meio acadêmico como, por exemplo, a já histórica dissertação de mestrado de Paz (2005) que, ao investigar o fenômeno da avaliação na educação infantil, verificando sua ocorrência nos trabalhos apresentados em todos os GTs nas Reuniões Anuais da ANPEd (Associação Nacional de Pesquisa e Pós-Graduação em Educação) em um período de onze anos, de 1993 a 2003, constatou a escassez de estudos sobre avaliação na educação infantil e a sua subordinação aos modelos avaliativos do ensino fundamental.

Na busca por subsídios que contribuam com o debate acerca da avaliação da educação infantil no Brasil, merece destaque a caracterização de iniciativas desenvolvidas nos Estados Unidos, na Espanha, na Itália, no México e na Austrália engendradas por Sousa e Pimenta (2016), que investigaram, ainda, pesquisas brasileiras apoiadas nestas experiências estrangeiras.

\footnotetext{
${ }^{4}$ Este texto é uma síntese da pesquisa Avaliação na Educação Básica (1990-1998), Barreto; Pinto (2001). Disponível em: <http://smeduquedecaxias.ri.gov.br/nead/Biblioteca/Forma\%C3\%A7\%C3\%A30\%20Continuada/Avalia\%C3\%A7\%C 3\%A30/avaliacao_ed_basica9098.pdf $>$.
} 
Moro e Sousa (2014) também identificaram 18 trabalhos no âmbito das investigações acadêmicas publicadas no Brasil, entre 1997 e 2012, que utilizam instrumentos avaliativos internacionais.

No âmbito do Projeto Formação da Rede em educação infantil: avaliação do contexto (2013), desenvolvido em parceria entre a Universidade Federal do Paraná/UFPR, Universidade Federal do Rio de Janeiro/UFRJ, Universidade Federal de Minas Gerais/UFMG, Universidade do Estado de Santa Catarina/UDESC, MEC e as pesquisadoras Anna Bondioli e Donatella Savio da Universidade de Pavia/ Itália, foi realizado um levantamento bibliográfico sobre avaliação em educação infantil, este entendido como avaliação da criança; institucional e política de avaliação. O levantamento mapeou as produções de 1997 a 2012 e identificou 65 trabalhos, sendo apenas sete teses, 35 dissertações e 24 artigos. Das sete teses, três tem como foco a questão da avaliação de contexto e quatro a avaliação da criança; já 18 das dissertações identificadas se enquadram na discussão de avaliação de contexto, 11 na avaliação da criança e seis mesclam ambos os temas. A maioria dos artigos (17) focam no contexto, cinco na criança e dois na articulação contexto/criança.

Artigos mais recentes, como de Moro (2016), Oliveira (2016), Campos (2016) e Didonet (2016), explicitam as divergências existentes em relação à utilização de métodos e instrumentos padronizados de avaliação na primeira infância e evidenciam o longo caminho a ser percorrido pela área da educação infantil no Brasil na consolidação de modelos avaliativos que garantam os direitos da criança e a especificidade desta etapa.

As controvérsias acerca da avaliação da educação infantil também foram alvo de análise de Sousa (2014) que, ao investigar indicadores advindos de diferentes iniciativas, explicitou duas tendências que demarcam propostas em disputa relacionada ao entendimento sobre qualidade da educação infantil, sendo que uma tendência prioriza as condições da oferta e a outra, o desempenho de alunos.

Frente ao cenário apresentado, marcado por lacunas, contradições e disputas, partimos da premissa de Sousa (2014, p. 73), para quem:

A implementação de um processo avaliativo supõe, necessariamente, a explicitação de qual é a situação desejável, o que se traduz em 
indicadores, critérios e padrões que serão tomados como referência para a consecução do julgamento e encaminhamentos de decisões relativas ao contexto avaliado. Ao se definirem que indicadores serão tomados como referência para avaliação se está explicitando qual a noção de qualidade que se está assumindo como referência para análise da realidade e indução de sua transformação.

Nesse sentido, compreender as iniciativas de avaliação na educação infantil e os instrumentos utilizados pelos diferentes municípios brasileiros, bem como os princípios e noção de qualidade em que eles se ancoram, parece ser relevante no momento atual em que uma política nacional de avaliação que contemple a etapa da educação infantil está sendo gestada.

Com esse intuito, buscaremos neste artigo apresentar um recorte da pesquisa (RIBEIRO, 2016), integrante do Projeto UNESCO BRZ/10415 , que teve por objetivo produzir insumos sobre a avaliação da aprendizagem das crianças matriculadas na primeira etapa da Educação Básica visando fomentar o debate na área. Neste estudo, nos ateremos a apresentar os dados referentes ao mapeamento e análise das iniciativas e/ou orientações municipais de avaliação de crianças matriculadas na educação infantil e $1^{\circ}$ ano do ensino fundamental, bem como os diferentes instrumentos avaliativos decorrentes destas propostas, de forma a melhor compreender se estas iniciativas estão caminhando na perspectiva de construção de uma avaliação que esteja alinhada à identidade e ao currículo da educação infantil.

Entendemos que em um momento profícuo como este, vivido pela área, a identificação e análise desses dados pode contribuir com o debate em curso no país sobre a delimitação do campo da avaliação em educação infantil.

\section{Avaliação da aprendizagem das crianças: bases legais}

Desde sua promulgação, em 1996, a LDB (9.394/96) já preconizava que a avaliação na educação infantil devia ser realizada mediante o acompanhamento e registro do desenvolvimento das crianças, sem o objetivo de seleção, promoção ou classificação, mesmo para o acesso ao ensino fundamental.

\footnotetext{
${ }^{5}$ De acordo com o edital 01/2015, Projeto 914/UNESCO/1009.4, consultor 13.
} 
O Parecer 17/2012 do Conselho Nacional/CNE/CEB reafirma essa ideia e explicita que não é admissível, nessa etapa, a utilização de provinhas ou outros instrumentos de avaliação que submetam as crianças a qualquer forma de ansiedade, pressão ou frustração (BRASIL, 2012, p. 11). Nessa mesma linha, estipula que a avaliação será sempre da criança em relação a si mesma e não comparativamente com outras crianças, sendo competência da escola sua realização.

A predominância do caráter formativo sobre o somativo em relação à avaliação da aprendizagem é insistentemente lembrada e recomendada pelo Conselho Nacional de Educação, em mais de um Parecer (BRASIL,2013 p. 52). Nessa perspectiva, os procedimentos criados pelas instituições de educação infantil para avaliação do trabalho pedagógico e das conquistas das crianças devem ter como meta, de acordo com Parecer CNE/CEB 20/2009, servir de "instrumento de reflexão sobre a prática pedagógica na busca de melhores caminhos para orientar as aprendizagens das crianças" (BRASIL, 2009).

Assim, as alterações realizadas na LDB através da Lei n.12.796/2013 caminham no sentido de ratificar os princípios já expressos anteriormente, e também introduzir um dispositivo de controle social da avaliação, na perspectiva da garantia do direito à aprendizagem das crianças e seu pleno desenvolvimento, o que segundo Campos (2012) é esperado em uma sociedade democrática, na qual todas as instituições e políticas públicas, inclusive as educacionais, devem ter acompanhamento e serem submetidas ao controle social.

Essa perspectiva se traduz, na inclusão do item V na LDB (BRASIL, 2013) que postula que as instituições educacionais devem expedir "documentação que possibilite atestar os processos de desenvolvimento e aprendizagens da criança". O que significa que os registros de cada criança, realizados no âmbito da instituição educacional, deverão acompanhar o seu percurso de aprendizagem, sendo encaminhados à instituição que a receberá no ano seguinte, seja de educação infantil ou ensino fundamental.

É importante frisar, entretanto, que essa documentação não pode ser entendida como um ato de julgar, punir ou rotular as crianças, nem os profissionais que com elas atuam. Seu objetivo é propiciar que o percurso de aprendizagem da criança seja 
compreendido de forma não fragmentada e que esta documentação favoreça seu pleno desenvolvimento.

Se o processo de elaboração da documentação deve ser realizado no âmbito da escola, a explicitação e normatização dessa documentação demanda, todavia, que os sistemas de ensino se posicionem, como já vem sendo feito por muitos municípios brasileiros, como São Paulo, 2014 e Maceió, 2015, entre outros.

Vale lembrar, entretanto, que essa normatização dos sistemas deve estar alinhada aos princípios já expressos nas DCNEI (BRASIL, 2010) que apontam cinco itens que devem ser garantidos no processo de acompanhamento do trabalho pedagógico e avaliação do desenvolvimento das crianças. São eles:

1. A observação crítica e criativa das atividades, das brincadeiras e interações das crianças no cotidiano;

2. Utilização de múltiplos registros realizados por adultos e crianças (relatórios, fotografias, desenhos, álbuns, etc.),

3. A continuidade dos processos de aprendizagens por meio da criação de estratégias adequadas aos diferentes momentos de transição vividos pela criança (transição casa/instituição de Educação Infantil, transições no interior da instituição, transição creche/pré-escola e transição pré-escola/Ensino Fundamental);

4. Documentação específica que permita às famílias conhecer o trabalho da instituição junto às crianças e os processos de desenvolvimento e aprendizagem da criança na educação infantil e

5. A não retenção das crianças na Educação Infantil. (BRASIL, 2010, p. 29)

Os princípios definidos na legislação e documentos orientadores e normativos da área, aqui explicitados, revelam que existe uma coerência entre o histórico da educação infantil no país, seus fins, objetivos e a forma de avaliação proposta para esta etapa. No entanto, o desafio que se impõe aos sistemas de ensino e instituições de educação infantil não é de ordem legal e, sim, de operacionalização da proposta que exige ruptura de práticas fortemente arraigadas.

Isso porque, a inclusão do inciso $\mathrm{V}$ na $\mathrm{LDB}$, ao lançar luz à questão da documentação dos processos de desenvolvimento e aprendizagem das crianças, trouxe à tona questões sobre a documentação pedagógica e consequentemente questões que 
interrogam não somente a avaliação, mas o próprio cerne da educação infantil, uma vez que a documentação é reveladora de concepções, práticas, planejamento e currículo.

Nesse sentido, conforme já discutido por Ribeiro (2015a), refletir sobre avaliação através dos processos de documentação pedagógica é refletir sobre as especificidades da primeira etapa da Educação Básica, buscando melhor definir seus contornos e escolhas que traduzem os objetivos e fins esperados para as crianças que frequentam a educação infantil.

Do ponto de vista legal, muitos são os parâmetros ${ }^{6}$ que expressam a noção de qualidade almejada para esta etapa da educação, assim como também os princípios orientadores da avaliação a ser realizada na educação infantil.

O quadro 1, a seguir, sintetiza os princípios que orientam a avaliação da aprendizagem das crianças matriculadas na educação infantil dispostos nos documentos normativos e na legislação mencionados anteriormente.

Quadro 1: Avaliação da aprendizagem na educação infantil: princípios legais

\begin{tabular}{|c|c|c|}
\hline & $\begin{array}{lll}\text { Princípios norteadores } & \text { da } \\
\text { avaliação da aprendizagem na } & \text { na } \\
\text { educação infantil } & \end{array}$ & $\begin{array}{l}\text { Ações que NÃO se alinham à } \\
\text { legislação vigente relativa à } \\
\text { avaliação da aprendizagem na } \\
\text { educação infantil }\end{array}$ \\
\hline Quem realiza? & Escola. & Instâncias e atores externos. \\
\hline $\begin{array}{l}\text { Para quê? } \\
\text { (Objetivo) }\end{array}$ & \begin{tabular}{lllr} 
Acompanhar o & \multicolumn{2}{c}{ percurso de } \\
desenvolvimento & da & criança, \\
qualificando & as & práticas \\
pedagógicas. & & & \\
\end{tabular} & $\begin{array}{l}\text { Selecionar, promover ou classificar } \\
\text { as crianças. }\end{array}$ \\
\hline $\begin{array}{c}\text { Como? } \\
\text { (metodologia) }\end{array}$ & $\begin{array}{l}\text { Mediante acompanhamento e } \\
\text { registro do desenvolvimento da } \\
\text { criança. }\end{array}$ & $\begin{array}{l}\text { Utilizando provinhas ou outros } \\
\text { instrumentos de avaliação que } \\
\text { submetam a criança à ansiedade, } \\
\text { pressão ou frustração. }\end{array}$ \\
\hline $\begin{array}{l}\text { Ponto de partida } \\
\text { da avaliação }\end{array}$ & $\begin{array}{l}\text { A criança e seus direitos } \\
\text { fundamentais. }\end{array}$ & $\begin{array}{l}\text { Conhecimentos estanques e } \\
\text { fechados por faixa etária ou a } \\
\text { criança em comparação com as } \\
\text { demais da turma. }\end{array}$ \\
\hline Frequência & Contínua. & Pontual. \\
\hline
\end{tabular}

Fonte: A autora, 2017.

\footnotetext{
${ }^{6}$ Ver Ribeiro, 2015b.
} 
Se os princípios apresentados são suficientes, compreendidos e/ou utilizados pelas redes municipais de educação infantil é exatamente o que nos interessou averiguar através do estudo das práticas e instrumentos avaliativos utilizados nos diferentes municípios brasileiros.

\section{Análise dos dados}

A metodologia utilizada na pesquisa envolveu o estudo da legislação e de orientações legais vigentes relacionadas à temática, levantamento de estudos nacionais e internacionais sobre avaliação da aprendizagem na educação infantil, envio de um Survey para conselheiros e dirigentes municipais de Educação, análise documental de instrumentos de avaliação utilizados por redes e unidades de educação infantil e um estudo de caso sobre as (des)articulações entre educação infantil e ensino fundamental.

No presente artigo, conforme já mencionado, nos limitaremos a comentar os principais resultados referentes à análise dos questionários e instrumentos avaliativos que tinham por objetivo melhor compreender como os municípios estavam interpretando, implementando e orientando as unidades educacionais em relação à avaliação da aprendizagem das crianças na educação infantil e $1^{\circ}$ ano do Ensino fundamental.

O questionário para conselheiros/as e dirigentes municipais de educação continha oito questões ${ }^{7}$ fechadas e três abertas e foi distribuído durante a realização do XXV Encontro Nacional dos Conselheiros Municipais de Educação, realizado em Ipojuca-PE, em outubro de 2015. Do total de 300 questionários distribuídos, obtivemos um retorno de 206, representativos de 125 municípios brasileiros, distribuídos em 22 estados.

Para análise dos dados recolhidos, os questionários foram numerados ${ }^{8}$ e as respostas foram codificadas e inseridas em uma planilha de dados. As primeiras

\footnotetext{
7 As questões foram elaboradas tendo como base os subsídios presentes nos seguintes documentos e materiais: (i) Programa Nacional de Capacitação de Conselheiros Municipais de Educação Pró-Conselho; (ii) O papel dos Conselhos Municipais de Educação (CME) no Sistema de Ensino Local. Prof. Dr. Francisco Soares Santos Filho; (iii) CURY, C. R. J. Conselhos de Educação: fundamentos e funções. RBPAE 22 (1): 41-67. Jan/Jun 2006; (iiii) CME: atribuições. Prefeitura BH. Foi realizada, ainda, consulta dos materiais disponíveis no site da UNCME e CME-SP.

${ }^{8}$ I. O primeiro dígito refere-se à identificação do sujeito respondente do questionário (Conselheiro Municipal de Educação, Dirigente Municipal de Educação ou Outro) e o dígito seguinte identifica o
} 
distribuições de respostas foram analisadas e, a partir delas, foi composta uma amostra 9 de 125 questionários, representantes de 125 diferentes municípios brasileiros.

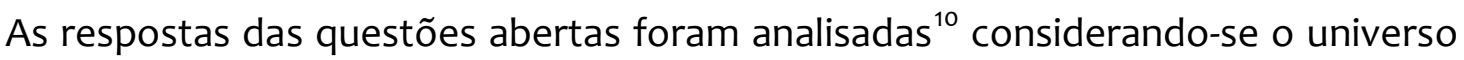
total de respondentes, ou seja, 206 questionários.

As informações obtidas por meio dos questionários expressam, conforme podemos visualizar pelo gráfico 1, as respostas de 167 Conselheiros/as Municipais de Educação (81\%), 14 Dirigentes Municipais de Educação (7\%) e 22 respondentes (11\%) que se identificaram como técnicos pedagógicos do CME, Secretária Executiva do CME, Coordenador Executivo do CME ou Coordenador Estadual do UNCME (União Nacional dos Conselhos Municipais de Educação), sendo, portanto, considerados na categoria “outros" de acordo com o questionário. Obtivemos, ainda, a abstenção dessa questão em três questionários (0,1\%).

\section{Gráfico 1: Sujeitos participantes do estudo}

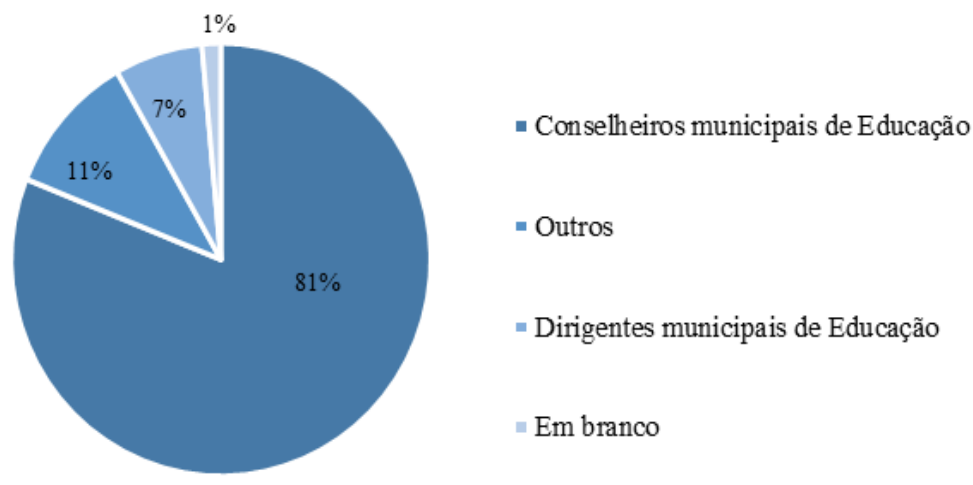

município do respondente por ordem alfabética, sendo que os questionários que correspondem ao mesmo município ainda ganharam uma terceira codificação com letras de acordo com o tipo do respondente (ex. Município de Ingazeira do Norte 2-1A, 2-1B...).

9 Os critérios utilizados para definição da amostra foram: 1. Para as questões objetivas, cada município poderia ter apenas uma resposta computada; 2 . As respostas deveriam ser prioritariamente advindas do Conselheiro do município e, na ausência deste se utilizou a resposta do Dirigente Municipal. Os questionários restantes (81), que representavam diferentes respondentes do mesmo município, foram separados para terem suas respostas analisadas apenas nas questões abertas.

${ }^{10}$ Para sua análise foram utilizados os seguintes procedimentos: 1) As respostas foram digitadas em uma planilha de dados; 2) Foram elaboradas categorias preliminares para classificação das respostas; 3) As categorias foram revisadas e, em muitos casos, agrupadas visando sua redução para fins de tabulação; 4) As categorias foram descritas através da elaboração de legendas com os conceitos-chave de cada grupo de respostas. 5) Foi realizado o processamento das respostas por categorias. 


\begin{tabular}{l|c|c}
\hline $\begin{array}{l}\text { Sujeitos } \\
\text { Conselheiros municipais de } \\
\text { Educação }\end{array}$ & N & $\%$ \\
\hline Dirigentes municipais de Educação & 167 & 81 \\
\hline Outros & 22 & 7 \\
\hline Em branco & 3 & 11 \\
\hline Total de sujeitos & 206 & 100 \\
\hline
\end{tabular}

Fonte: A autora, 2017.

Ao realizarmos a distribuição dos questionários por regiões brasileiras, pode-se constatar a grande concentração de representantes de municípios da região nordeste $(60 \%)^{11}$ do país, seguido por uma grande diferença da região sudeste (16\%), depois norte (11\%) e com apenas $7 \%$ e $6 \%$ a região sul e centro-oeste, respectivamente. No entanto, se situarmos os 125 respondentes que compõem a amostra nos diferentes estados brasileiros, verificaremos que 22 estados estão contemplados conforme ilustrado pela figura 1 a seguir.

Figura 1: Distribuição da amostra por estados e regiões.

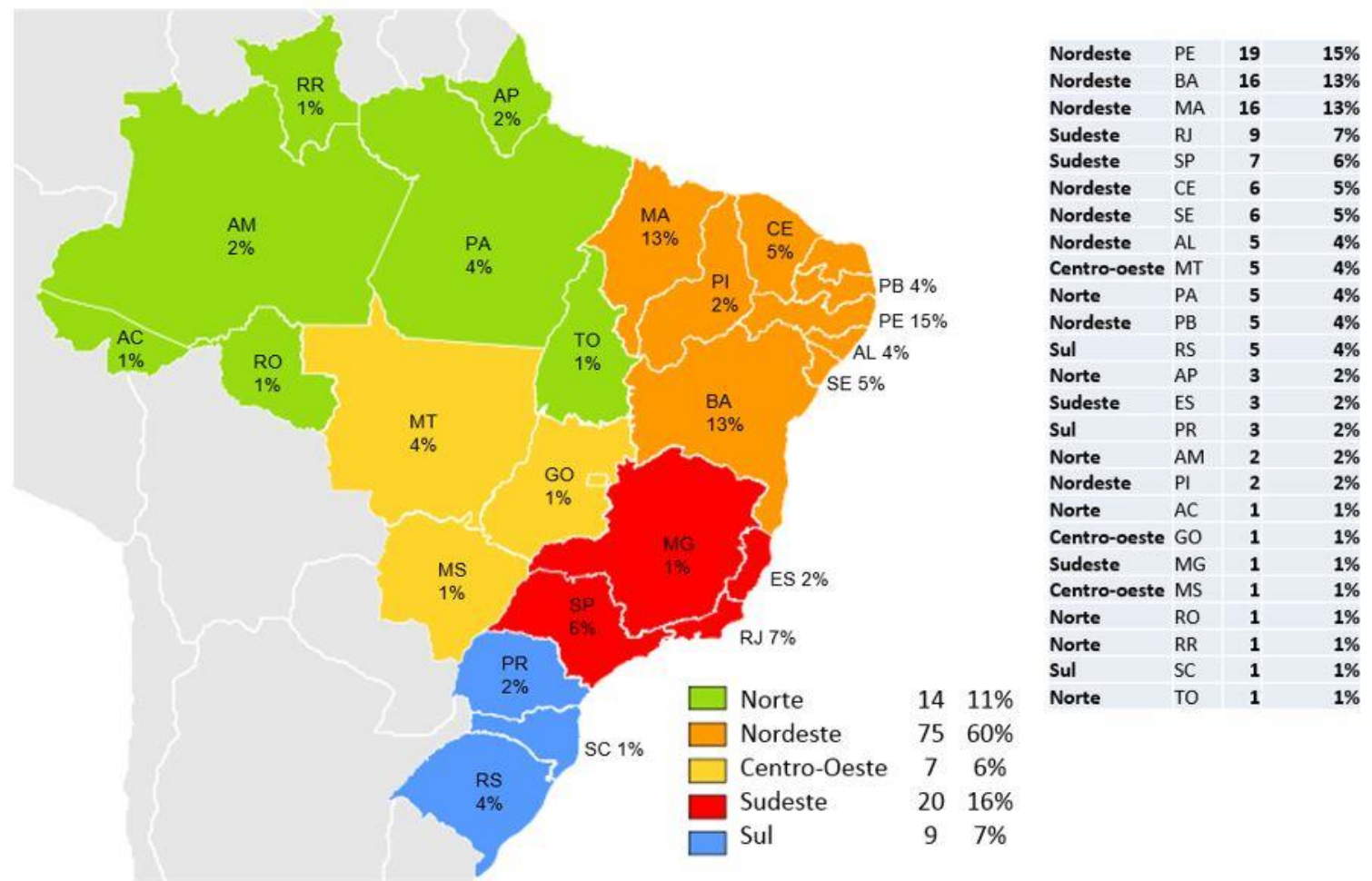

Fonte: A autora, 2017.

\footnotetext{
${ }^{11}$ Dado esperado uma vez que o evento, onde os questionários foram distribuídos e recolhidos, se deu nessa região.
} 
As primeiras questões do questionário tinham por objetivo coletar dados sobre o perfil do município, por isso foi indagado se o município possuía Sistema Municipal de Ensino Próprio. Responderam afirmativamente $83 \%$ dos sujeitos escutados e $16 \%$ indicaram que seu município não possui Sistema Municipal de Ensino Próprio. Houve um caso, ainda, de um respondente que não soube informar esse dado.

Em seguida, foi questionado se o Conselho Municipal de Educação já havia emitido alguma orientação para o Sistema Municipal de Ensino em relação à implementação da Lei $n^{\circ} 12.796 / 13$. As respostas ficaram divididas: 47\% afirmou que o CME de seu município não emitiu parecer sobre a expedição de documentação que ateste os processos de desenvolvimento e aprendizagem das crianças e 43\% assinalou que o CME já emitiu parecer, cumprindo, assim, seu papel de orientar na implementação da legislação brasileira.

O questionário visava verificar ainda se o Plano Municipal de Educação continha alguma orientação relacionada à avaliação das crianças ou instituições de educação infantil; $68 \%$ informou que o documento contém orientação, $18 \%$ que não e, o restante, não soube informar ou deixou a questão em branco.

Foi perguntado, ainda, se os municípios realizavam algum tipo de avaliação das crianças que ingressam no $1^{\circ}$ ano do ensino fundamental, portanto, recém-saídas da educação infantil; 29\% das respostas apontaram que os municípios realizam algum tipo de avaliação destas crianças. Para as respostas assinaladas positivamente, o questionário pedia que os respondentes descrevessem os conteúdos avaliados e no que consistia essa avaliação.

As respostas foram então agrupadas em seis grandes categorias que, todavia, não expressam apenas os conteúdos das avaliações, conforme esperado. Foi necessária a criação de categorias relativas a procedimentos (avaliação por meio da observação e registro), fins (avaliação diagnóstica) e até modalidade avaliativa (avaliação em larga escala) para que todas as respostas fossem devidamente contempladas na análise.

O quadro 2, a seguir, apresenta uma síntese das categorias advindas da análise das questões abertas do questionário e suas respectivas descrições, nos permitindo constatar que a continuidade do processo de aprendizagem (e consequentemente o de avaliação) e 
o cuidado com as transições das crianças, tão enfatizado por documentos como as DCNEB (BRASIL,2013), as DCNEI (BRASIL,2010), ainda são pouco praticados no universo estudado.

Quadro 2: Categorização das declarações sobre as avaliações realizadas no $1^{\circ}$ ano do Ensino Fundamental e suas respectivas descrições

\begin{tabular}{|c|c|}
\hline Categorias & Descrição \\
\hline $\begin{array}{l}\text { Avaliação de } \\
\text { Conteúdos de } \\
\text { português e } \\
\text { matemática }\end{array}$ & $\begin{array}{l}\text { Nesta categoria foram reunidas as respostas em que a avaliação consiste na } \\
\text { aferição de conteúdos relacionados exclusivamente a português e matemática, } \\
\text { leitura e escrita, conhecimento do alfabeto. As respostas mencionaram, ainda, que } \\
\text { essas avaliações se embasavam no PNAIC, ANA e provinha Brasil. Foi feita menção, } \\
\text { também, sobre a realização de avaliação escrita e oral com crianças de } 4 \text { a } 5 \text { anos e } \\
1^{\circ} \text { ano do EF. }\end{array}$ \\
\hline $\begin{array}{l}\text { Avaliação de } \\
\text { Competências e } \\
\text { habilidades }\end{array}$ & $\begin{array}{l}\text { As respostas aqui agrupadas se referem à realização de avaliação individual da } \\
\text { criança por meio de pareceres individuais e fichas de registro de competências e } \\
\text { habilidades relacionadas a aspectos físicos, cognitivos, afetivos, comportamentais, } \\
\text { interpessoais e psicomotores. }\end{array}$ \\
\hline Avaliação diagnóstica & $\begin{array}{l}\text { As respostas aqui reunidas fazem menção à realização de avaliação diagnóstica } \\
\text { inicial e descritiva visando identificar o nível de conhecimento da criança. }\end{array}$ \\
\hline $\begin{array}{l}\text { Avaliação por meio da } \\
\text { observação e registro }\end{array}$ & $\begin{array}{l}\text { Nesta categoria foram reunidas as respostas que mencionam a realização da } \\
\text { avaliação por meio da observação e registro do desenvolvimento das crianças e } \\
\text { uso do portfólio para acompanhamento do desenvolvimento. }\end{array}$ \\
\hline $\begin{array}{l}\text { Avaliações em larga } \\
\text { escala/padronizadas }\end{array}$ & $\begin{array}{l}\text { Esta categoria reúne respostas que citam a realização de avaliações padronizadas } \\
\text { para toda a rede municipal visando verificar o processo de ensino e aprendizagem. }\end{array}$ \\
\hline $\begin{array}{c}\text { Avaliação em processo } \\
\text { de elaboração e/ou } \\
\text { revisão }\end{array}$ & $\begin{array}{l}\text { As respostas aqui reunidas mencionaram que a avaliação do município está em } \\
\text { processo de elaboração ou revisão, devido à necessidade de adequações de seu } \\
\text { conteúdo. }\end{array}$ \\
\hline Outros & $\begin{array}{l}\text { Nesta categoria foram agrupadas as respostas que não especificaram o conteúdo } \\
\text { das avaliações realizadas, como por exemplo, matrizes e descritores, avaliação da } \\
\text { criança, avaliação feita através da escola. }\end{array}$ \\
\hline
\end{tabular}

Fonte: Ribeiro, 2017.

A análise dos dados evidenciou que, dos municípios que afirmam realizar avaliações com as crianças egressas da educação infantil, $25 \%$ têm como foco exclusivo a Avaliação de conteúdos de português e matemática; seguido, pela Avaliação de competências e habilidades, mencionada por $19 \%$ das respostas e que consiste na elaboração de pareceres individuais e/ou fichas de registro de competências e habilidades relacionadas a aspectos físicos, cognitivos, afetivos, comportamentais, interpessoais e psicomotores. Também com 19\% das menções aparecem as respostas que afirmam que 
seus municípios realizam avaliação diagnóstica inicial e descritiva visando identificar o nível de conhecimento da criança.

A Avaliação por meio da observação e registro foi citada em $14 \%$ das respostas que afirmaram que o acompanhamento do desenvolvimento da criança se dá por meio da observação, registro e uso do portfólio. Em seguida, foram agrupadas as respostas (8\%) que apenas mencionaram que seus municípios fazem uso das Avaliações em larga escala/padronizadas, que consistem, segundo informado, em avaliações padronizadas para toda a rede municipal visando verificar o processo de ensino e aprendizagem.

E, por último, ficaram as respostas (5\%) agrupadas na categoria denominada Avaliação em processo de elaboração e/ou revisão. Foi necessária, ainda, a criação da categoria "Outros" destinada a agrupar as respostas que não especificaram o conteúdo das avaliações realizadas, citando apenas itens como: matrizes e descritores, avaliação da criança, avaliação feita através da escola.

A análise das respostas das questões abertas evidenciou ainda que grande parte dos mais de 200 gestores públicos participantes do estudo reconhece que possui pouco ou nenhum repertório e referência sobre avaliação em educação infantil e pede auxílio com maiores informações advindas do governo federal.

Os dados obtidos por meio dos questionários foram aprofundados através da realização de uma amostra aleatória $^{12}$ que teve por objetivo realizar uma análise documental de caráter qualitativo dos instrumentos produzidos pelas equipes técnicas das Secretarias Municipais de Educação para serem utilizados pelas unidades de educação infantil para acompanhamento da aprendizagem das crianças.

No total, foram analisados 23 instrumentos avaliativos de diferentes municípios provenientes da região sudeste e nordeste do país. A escolha metodológica de analisar os instrumentos a partir de quatro eixos de análise se deu, em parte, devido ao tempo exíguo e também por entendermos que esses quatro elementos nos permitem ter uma clara visão sobre as características gerais dos instrumentos, bem como da concepção de criança e educação subjacente a eles, uma vez que "da mesma forma que as paredes

\footnotetext{
${ }^{12}$ Nossa amostra foi composta de forma aleatória através da livre adesão dos municípios envolvidos que cederam voluntariamente o material para análise.
} 
'falam' sobre a pedagogia praticada, os instrumentos de avaliação também comunicam a concepção de criança e educação infantil” (MACEIÓ, 2015, p. 178).

Os eixos definidos para análise dos materiais e suas respectivas descrições, bem como as categorias identificadas através do estudo dos instrumentos, são descritos no quadro síntese a seguir.

Quadro 3: Quadro-síntese das categorias identificadas nos instrumentos analisados

\begin{tabular}{|c|c|c|}
\hline EIXO & DESCRIÇÃO & CATEGORIAS IDENTIFICADAS \\
\hline \multirow[b]{3}{*}{ FREQUÊNCIA } & \multirow{3}{*}{$\begin{array}{l}\text { Neste item, nos interessa } \\
\text { identificar com que frequência a } \\
\text { avaliação em questão é realizada } \\
\text { com as crianças, se acontece de } \\
\text { forma contínua ou em momentos } \\
\text { pontuais. QUANDO ocorre? }\end{array}$} & 1. Trimestral \\
\hline & & 2. Semestral \\
\hline & & 3. Anual \\
\hline \multirow{4}{*}{ SUJEITOS } & \multirow{4}{*}{$\begin{array}{l}\text { As perguntas a serem investigadas } \\
\text { aqui são: QUEM realiza/participa } \\
\text { da avaliação? Quais são os sujeitos } \\
\text { participantes da avaliação? }\end{array}$} & 1. Professoras/es \\
\hline & & 2. Professoras/es e familiares \\
\hline & & 3. Professoras/es e crianças \\
\hline & & 4. Professoras, familiares e crianças \\
\hline \multirow{3}{*}{ METODOLOGIA } & \multirow{3}{*}{$\begin{array}{l}\text { Este item objetiva compreender } \\
\text { COMo as crianças são avaliadas? } \\
\text { Qual o formato da avaliação? Qual } \\
\text { a metodologia proposta para } \\
\text { acompanhamento } \\
\text { aprendizagens das crianças? }\end{array}$} & $\begin{array}{l}\text { 1. Relatório individual da criança } \\
\text { realizado com ou sem o apoio de } \\
\text { itens de observação, que } \\
\text { variavam entre } 03 \text { a } 12 \text { itens. }\end{array}$ \\
\hline & & $\begin{array}{l}\text { 2. Fichas para preenchimento do } \\
\text { professor de acordo com } \\
\text { legendas ou opções } \\
\text { apresentadas }{ }^{13} \text {. }\end{array}$ \\
\hline & & $\begin{array}{l}\text { 3. Relatório com texto padrão para } \\
\text { o professor apenas inserir o nome } \\
\text { da criança e a palavra sim ou não } \\
\text { na frente dos enunciados. }\end{array}$ \\
\hline CONTEÚDO & $\begin{array}{l}\text { O foco deste item consiste em } \\
\text { investigar o QUÊ é avaliado? No } \\
\text { que consiste a avaliação? }\end{array}$ & \\
\hline
\end{tabular}

Fonte: A autora, 2018.

Em relação à frequência das avaliações, foi possível constatar que em 13 casos os registros sobre acompanhamento da aprendizagem das crianças são realizados semestralmente, sendo uma vez no início e a outra no final do ano; oito são preenchidos a cada trimestre e dois apenas no final do ano.

\footnotetext{
13 Exemplos de legendas identificadas nessa tipologia: $S=\operatorname{sim}, N=$ não, $R=$ raramente, $D=e m$ desenvolvimento; sim, não, às vezes; tranquila, chorou muito, apresentou muita dificuldade.
} 
Chama a atenção que em nenhum dos 23 documentos analisados a avaliação do acompanhamento das crianças é entendida como um processo contínuo, conforme orientação legal, e sim como um momento pontual que ocorre para operacionalização de uma demanda da rede.

A análise sobre os sujeitos envolvidos no processo avaliativo constatou que a maioria dos registros (17) era feita exclusivamente pelas professoras; quatro continham espaço para observação e/ou opinião da família; em um havia espaço para criança e também somente um dos instrumentos abria espaço para professoras, famílias e crianças. No entanto, ao procedermos com uma análise mais qualitativa visando à compreensão do "espaço" destinado às crianças e famílias, ficou evidente que a inclusão de outros atores, além da professora, não significava necessariamente a inclusão de novos olhares ou perspectivas. Como, por exemplo, o espaço destinado às crianças em dois instrumentos se restringia a um local onde elas deveriam realizar um desenho (eu sou assim) e escrever seu nome, para que os pais pudessem acompanhar o desenvolvimento da escrita do nome e do desenho da criança, ou seja, não se tratava de incluir o olhar da criança no processo avaliativo, mas apenas, nos dizeres de um dos documentos analisados, ilustrar o relato da professora com "amostras de produção escrita das crianças".

Os cinco instrumentos que continham espaço para família também não evidenciavam uma construção coletiva em relação ao acompanhamento das aprendizagens e desenvolvimento das crianças, apenas havia um pequeno espaço para observação abaixo do relato da professora, onde a família deveria assinar dando ciência que leu o relatório e, se quisesse, poderia inserir algum comentário.

Os dados sobre participação dos atores dialogam com os dados do eixo de frequência, uma vez que em uma concepção na qual a avaliação é entendida como um momento pontual, a participação na avaliação também se traduz como um momento pontual, seja das professoras, crianças ou familiares que são convidados a participar em momentos e com ações específicas.

Em relação à metodologia utilizada pelos instrumentos analisados, foi possível identificar três tipologias específicas, conforme já descritas no quadro 3. A tipologia 1 (relatório descritivos individuais) e 2 (fichas para preenchimento de acordo com legenda) 
foram as mais recorrentes, sendo 10 instrumentos de cada; já a tipologia 3 (relatório com texto padrão para todas as crianças) apareceu 3 vezes no universo em questão. Se desmembrarmos a categoria 1 em relatos escritos com apoio de itens ${ }^{14}$ e relatos sem itens previamente estabelecidos, identificaremos, respectivamente, 06 e 04 instrumentos.

Após conhecido o formato dos instrumentos, procedemos com análises distintas de seu conteúdo de acordo com as tipologias identificadas. Para as avaliações de Tipo 1 foram analisados tanto os itens propostos pelo próprio documento para observação, como o registro das professoras cujas avaliações não possuíam itens de referência.

Essa análise revelou que tanto os documentos com itens de referência prédefinidos pela Secretaria Municipal de Educação, como os instrumentos que deixavam a escolha do que observar a critério dos/as professores/as, recaiam sobre as mesmas pautas de observação. O quadro 4 a seguir revela que os dois primeiros itens (item 1 e 2) aparecem somente em um documento destinado às crianças de 0 a 3 anos, já os demais itens ( 3 a 10) são mencionados em todos os 10 documentos pertencentes a essa tipologia, havendo apenas pequenas variações no que se refere à nomenclatura dos itens (conforme descrito na primeira coluna do quadro).

Quadro 4: Conteúdo das avaliações de aprendizagem identificados na tipologia 1

\begin{tabular}{|c|c|}
\hline $\begin{array}{c}\text { Itens* para observação identificados nos } \\
\text { instrumentos tipo } 1\end{array}$ & Observação \\
\hline 1. Adaptação/desfralde & \multirow{2}{*}{$\begin{array}{l}\text { Itens citados em apenas um instrumento } \\
\text { destinado à creche. }\end{array}$} \\
\hline 2. Brincadeira & \\
\hline $\begin{array}{l}\text { 3. Relações sócio-afetivas, relação consigo e } \\
\text { com os outros, interação, comunicação }\end{array}$ & \multirow{6}{*}{$\begin{array}{l}\text { Itens mencionados em todos os documentos } \\
\text { pertencentes à tipologia } 1 .\end{array}$} \\
\hline $\begin{array}{l}\text { 4. Linguagem oral, leitura e escrita, interesse } \\
\text { e manuseio de materiais gráficos }\end{array}$ & \\
\hline $\begin{array}{l}\text { 5. Conhecimento lógico-matemático, } \\
\text { linguagem matemática }\end{array}$ & \\
\hline $\begin{array}{l}\text { 6. Compreensão de fenômenos naturais e } \\
\text { sociais, relação da criança com a natureza } \\
\text { e cultura, }\end{array}$ & \\
\hline $\begin{array}{l}\text { 7. Desenvolvimento } \\
\text { linguagem plástica }\end{array}$ artístico, artes, & \\
\hline 8. Movimento, linguagem corporal & \\
\hline
\end{tabular}

*A nomenclatura foi mantida de acordo com o original dos instrumentos analisados. Fonte: A autora, 2018.

\footnotetext{
${ }^{14}$ Neste tipo de instrumento, os itens a serem observados pelo/a professor/a já eram indicados no próprio documento. Ver quadro 4.
} 
No entanto, se por um lado parece existir um certo consenso das dimensões a serem observadas em relação ao processo de acompanhamento das aprendizagens das crianças, por outro, elas pouco dialogam com as diretrizes legais da área e as dimensões consideradas fundamentais para o desenvolvimento das crianças como, por exemplo, a brincadeira, tida como estruturante do currículo na educação infantil, segundo as DCNEI (BRASIL, 2010) e que nos instrumentos não aparece como um momento importante de ser observado e registrado. As linguagens infantis também aparecem de forma fragmentada e desarticulada, demandando um momento específico para ser trabalhado ao invés de ser fruto das vivências cotidianas.

A análise dessa tipologia revelou ainda, que embora os itens observados fossem semelhantes entre os instrumentos com e sem itens previamente estabelecidos, 0 conteúdo dos registros das crianças continha significativas diferenças: enquanto os primeiros detalhavam mais cada item e descritor previamente estabelecido, trazendo um olhar em maior profundidade, os relatos espontâneos eram extremamente sintéticos e simplificavam, por exemplo, o eixo matemática no seguinte registro: “conta até 10".

Além dos desafios já citados anteriormente, a análise desses registros permitiu ainda, a identificação de outros desafios a serem superados na tarefa de documentar a aprendizagem das crianças em ambos os casos. Segue, abaixo, uma síntese dos principais achados dessa tipologia.

Quadro 5: Principais desafios a serem superados identificados na análise das avaliações tipo 1

\begin{tabular}{|c|c|c|}
\hline Desafio & Consequências no relatório & Exemplo* ilustrativo \\
\hline $\begin{array}{c}1 . \\
\text { Construir um relatório } \\
\text { que expresse a } \\
\text { singularidade de cada } \\
\text { criança }\end{array}$ & $\begin{array}{l}\text { Relatórios com frases } \\
\text { idênticas das crianças apenas } \\
\text { em ordem diferente no corpo } \\
\text { do texto. }\end{array}$ & $\begin{array}{l}\text { O Kleiton é uma criança bastante } \\
\text { esperta, falante e com uma ótima } \\
\text { percepção das atividades da vida e } \\
\text { das suas relações, expressando } \\
\text { muito bem suas dificuldades, } \\
\text { solicitando ajuda, ajudando o } \\
\text { outro e percebendo as dificuldades } \\
\text { dos amigos e amigas. } \\
\text { A Melissa é uma criança bastante } \\
\text { esperta, falante e com uma ótima } \\
\text { percepção das atividades da vida e } \\
\text { das suas relações, expressando }\end{array}$ \\
\hline
\end{tabular}




\begin{tabular}{|c|c|c|}
\hline & & $\begin{array}{l}\text { muito bem suas dificuldades, } \\
\text { solicitando ajuda, ajudando o } \\
\text { outro e percebendo as dificuldades } \\
\text { dos amigos e amigas. }\end{array}$ \\
\hline & $\begin{array}{l}\text { Frases retiradas de outros } \\
\text { relatórios e que, às vezes, } \\
\text { geram frases contraditórias } \\
\text { sobre a mesma criança. }\end{array}$ & $\begin{array}{l}\text { Lucas apresenta muita ansiedade } \\
\text { Lucas é um menino muito calmo. }\end{array}$ \\
\hline $\begin{array}{c}2 . \\
\text { Construir uma efetiva } \\
\text { parceria família-escola }\end{array}$ & $\begin{array}{l}\text { Relatórios que apresentam } \\
\text { apenas as supostas } \\
\text { dificuldades das crianças, } \\
\text { sem mencionar a intervenção } \\
\text { da escola, a investigação } \\
\text { sobre as possíveis causas e } \\
\text { sem buscar o diálogo. Apenas } \\
\text { se remete à família a } \\
\text { necessidade de intervenção e } \\
\text { solução da questão. }\end{array}$ & $\begin{array}{l}\text { Rafael não apresenta } \\
\text { comportamento adequado, briga } \\
\text { com colegas, empurra, puxa o } \\
\text { cabelo das crianças, não faz sua } \\
\text { lição e não sabe brincar com os } \\
\text { amigos. É preciso que a família } \\
\text { tome imediatas providências. }\end{array}$ \\
\hline $\begin{array}{c}3 . \\
\text { Dar voz às crianças }\end{array}$ & $\begin{array}{l}\text { Documentação do processo } \\
\text { construída apenas sobre e } \\
\text { não com, somente sobre a } \\
\text { criança. }\end{array}$ & $\begin{array}{l}\text { Pouco uso e/ou ausência e } \\
\text { invisibilidade das vozes, olhares e } \\
\text { perspectivas das crianças. }\end{array}$ \\
\hline $\begin{array}{c}4 . \\
\text { Focar nas conquistas e } \\
\text { aprendizagens das } \\
\text { crianças }\end{array}$ & $\begin{array}{l}\text { Relatórios que enfocam } \\
\text { apenas as competências e } \\
\text { habilidades não adquiridas } \\
\text { pelas crianças, gerando listas } \\
\text { (semelhante à lista de } \\
\text { compras em mercado) de } \\
\text { itens que supostamente as } \\
\text { crianças estão em "falta" em } \\
\text { relação ao restante da turma. }\end{array}$ & $\begin{array}{l}\text { Matheus não adquiriu nesse } \\
\text { semestre as seguintes } \\
\text { competências básicas: } \\
\text { - Contar até } 10 \\
\text { - Escrever o nome } \\
\text { - Ficar sentado na roda de leitura } \\
\text { - Espera sua vez para falar na roda } \\
\text { de conversa. }\end{array}$ \\
\hline
\end{tabular}

*Exemplos transcritos dos instrumentos analisados contendo modificações apenas nos nomes das crianças citadas.

Fonte: a autora, 2018.

Em relação à análise do conteúdo das 10 avaliações caracterizadas como Tipo 2 (fichas para preenchimento de acordo com legendas), foi realizado o agrupamento das dimensões já existentes nos documentos e quando isso não era possível, utilizava-se a análise das perguntas que possibilitaram a classificação das respostas. Esse processo, resultou na identificação de oito grandes dimensões que se repetem em todos os instrumentos e que serão melhor ilustradas no quadro 6 a seguir. 
Quadro 6: Conteúdo das avaliações de aprendizagem identificados na tipologia 2

\begin{tabular}{|c|l|}
\hline $\begin{array}{c}\text { Dimensões* abordadas nos } \\
\text { instrumentos tipo 2 }\end{array}$ & Exemplo de questões** referentes às dimensões \\
\hline 1. Comportamento das crianças & $\begin{array}{l}\text { A criança demonstra certa rebeldia? Tem dificuldade } \\
\text { em obedecer? Desobedece pelo prazer de } \\
\text { contrariar? Possui curiosidade normal para sua } \\
\text { idade? Faz birra? }\end{array}$ \\
\hline $\begin{array}{l}\text { 2. Autonomia para alimentação e } \\
\text { atividades de cuidado pessoal }\end{array}$ & $\begin{array}{l}\text { Desempenha sozinho/a atividades de rotina como } \\
\text { comer e despir-se? }\end{array}$ \\
\hline $\begin{array}{l}\text { 3. Organização da criança em } \\
\text { relação aos materiais pessoais e e } \\
\text { brinquedos da sala }\end{array}$ & $\begin{array}{l}\text { A criança tem cuidado com os materiais da escola? É } \\
\text { organizado/a em seu trabalho? }\end{array}$ \\
\hline 4. Higiene da criança & $\begin{array}{l}\text { A criança chega "limpa e asseada à escola”? Possui } \\
\text { hábitos de higiene pessoal? }\end{array}$ \\
\hline 5. Coordenação motora/motricidade & $\begin{array}{l}\text { Sobe desce escada com firmeza? Pula numa perna } \\
\text { só? Tem dificuldade para andar em fila? Domina } \\
\text { atividades que dependem de movimentos amplos } \\
\text { (grandes músculos)? }\end{array}$ \\
\hline 6. Respeito às regras, limites e es \\
combinados & $\begin{array}{l}\text { Respeita os limites estabelecidos por suas } \\
\text { educadoras e amigos? }\end{array}$ \\
\hline 7. Linguagem oral e escrita & $\begin{array}{l}\text { Sabe reproduzir seu nome com ou sem modelo? } \\
\text { Reconhece alguns nomes dos colegas da classe? } \\
\text { Demonstra interesse em manusear livros de história? }\end{array}$ \\
\hline 8. Apoio das famílias & $\begin{array}{l}\text { As famílias apoiam as crianças e a escola em relação } \\
\text { às tarefas de casa? As famílias resolvem questões } \\
\text { comportamentais das crianças? A família realiza } \\
\text { cuidados pessoais da criança? }\end{array}$ \\
\hline
\end{tabular}

*Foram mantidos os nomes originais utilizados nos documentos.

**Questões transcritas de documentos analisados.

Fonte: A autora, 2018.

Sobre as dimensões abordadas nos instrumento de Tipo 2 vale destacar ainda, que a dimensão 5 (Coordenação motora/motricidade) trouxe diferentes abordagens sobre o tema, enquanto parte dos documentos abordava questões mais amplas de como a criança se movimenta e organiza seu corpo no espaço, em outros, apareciam questões bem específicas, que traduziam o que se concebia e se esperava que as crianças soubessem realizar, conforme descrito no quadro acima. A questão sobre a linguagem oral e escrita (dimensão 7) também apareceu de forma diversificada: em alguns tinha como foco específico a questão da apreensão da escrita do nome próprio e dos colegas, em outros, o objetivo era captar se a criança tinha aprendido habilidades específicas como o reconhecimento de algumas letras do alfabeto e havia, ainda, avaliações que 
focavam na função social da escrita e valorizavam itens como o prazer da criança em manusear e ouvir histórias.

Mais uma vez, chama a atenção o fato de questões essenciais para uma educação infantil de qualidade, de acordo com o já apontado no arcabouço legal da área, estarem ausentes ou serem tratadas de forma superficial e, inclusive, equivocada. Como no caso da questão da corporeidade, em que em nenhum momento foi relacionada ao autoconhecimento e construção da identidade das crianças e, sim, apenas restrita à aquisição de coordenação motora visando à escrita. As relações e interações tão fundamentais no trabalho com essa faixa etária também apareceram apenas restritas às questões comportamentais, limitando-se à verificação de brigas entre as crianças. A brincadeira, praticamente ausente na maioria dos instrumentos, quando era mencionada se destinava apenas a identificar as brincadeiras preferidas das crianças.

Nesse sentido, também é possível afirmar que os instrumentos Tipo 2 não dão conta do apregoado nas DCNEI que se pautam na “indivisibilidade das dimensões expressivo-motora, afetiva, cognitiva, linguística, ética, estética e sociocultural da criança" (BRASIL, 2010, p. 19).

Por fim, procedemos com a análise do conteúdo das avaliações Tipo 3, que consistiam em um texto padrão para o $1^{\circ}$ e outro para o $2^{\circ}$ semestre feito pela equipe técnica da Secretaria Municipal de Educação para toda a rede municipal, no qual os/as professores/as precisavam apenas inserir o nome da criança e em algumas passagens do texto inserir o "sim ou não" na frente do enunciado. O foco do documento se diferencia de acordo com o semestre em questão, sendo assim dividido:

No $1^{\circ}$ semestre, o foco do texto era voltado para descrever questões relativas à adaptação, desenvolvimento da identidade e autonomia, refeições, relações sócioafetivas, linguagem oral, registro escrito, conhecimento lógico-matemático, aspectos psicomotores e projetos trabalhados pela turma. Já o texto referente ao $2^{\circ}$ semestre enfatiza questões relativas à assiduidade e pontualidade da criança, linguagem e formação literária, raciocínio lógico-matemático, natureza e sociedade e expressão artística. 
No final do documento destinado ao $2^{\circ}$ semestre havia ainda o seguinte enunciado, transcrito a seguir, que deveria ser preenchido e assinado pela professora e coordenadora pedagógica da unidade educacional:

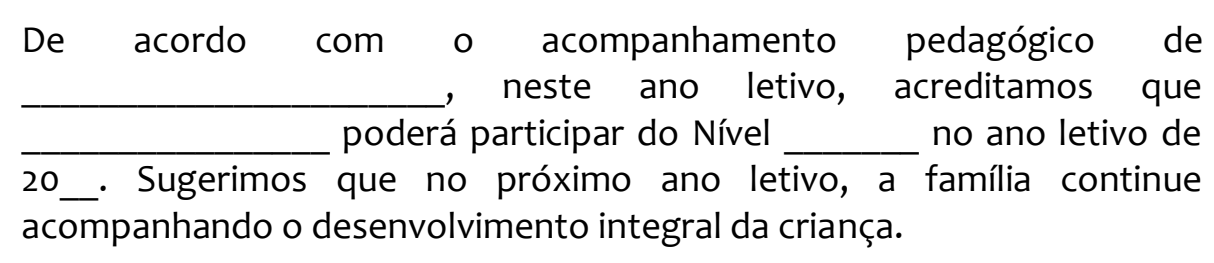

Sobre isso é importante recuperar que, conforme estabelecido pela LDB (9394/96), DCNEI (BRASIL, 2010) e de acordo com os Pareceres do CNE/CEB (20/2009 e 17/2012), a avaliação deve ter a "a finalidade de acompanhar e repensar o trabalho realizado" e nesse sentido "nunca é demais enfatizar que não devem existir práticas inadequadas de verificação da aprendizagem, tais como provinhas, nem mecanismos de retenção das crianças na Educação Infantil" (Parecer CNE/CEB 20/2009), ou seja, a seleção, promoção ou classificação das crianças, tal como consta no documento analisado, está em desacordo com a legislação vigente.

Vale lembrar, ainda, que a inclusão do inciso $V$, no artigo 31 da LDB (Lei 12.796/2013) “não apenas nega as pautas avaliativas tradicionais, que selecionam e classificam, mas sugere que as instituições de educação infantil se munam de instrumentos que documentem os processos de desenvolvimento e aprendizagem da criança" (MACEIÓ, 2015, p. 180) sem objetivo de seleção e, sim, visando favorecer o processo de aprendizagem e desenvolvimento as crianças.

\section{Considerações finais}

Os dados obtidos através do presente estudo apontam para a necessidade da área da educação infantil no Brasil, "sem fobia, ojeriza ou preconceito, mas com cuidado" (ROSEMBERG, 2013, p. 70), se inserir com mais força no atual debate sobre a construção da Política Nacional de Avaliação da Educação Básica, de forma a evidenciar a 
especificidade da educação infantil e, consequentemente, elaborar propostas avaliativas coerentes com esta etapa da educação.

Ficou evidente a escassez de materiais acadêmicos e da literatura em geral que abordem a questão da avaliação sob a perspectiva específica da educação infantil e a sua quase invisibilidade quando se trata de estudos mais amplos que realizam um balanço sobre avaliação na Educação Básica.

A análise dos questionários direcionados a Conselheiros e Dirigentes Municipais evidenciou, entre outras questões, que as crianças egressas da educação infantil estão sendo avaliadas tomando-se por referência uma concepção estreita de currículo e aprendizagem, restringindo-os à mera aquisição de competências e habilidades, em especial de língua portuguesa e matemática. São necessários outros estudos que busquem averiguar os possíveis impactos negativos destas avaliações no currículo da educação infantil, que pode passar a ser pautado pelos conteúdos da avaliação realizada no primeiro ano.

Os dados obtidos através da análise dos 23 instrumentos utilizados por diferentes municípios para acompanhamento da aprendizagem das crianças na educação infantil revelou o prevalecimento de avaliações padronizadas que desconsideram a singularidade de cada criança, seu percurso de aprendizagem individual e grupal e os condicionantes desse processo, mostrando-se assim, insuficientes não só como instrumento de documentação e avaliação do percurso, mas também como procedimento que busca favorecer a aprendizagem. Mesmo nos casos de avaliações da aprendizagem realizadas mediante documentação e registro através de relatórios individuais das crianças, prática avaliativa que mais se aproxima das orientações normativas para esta etapa, os desafios identificados foram muitos, evidenciando que há ainda um longo caminho a ser percorrido na construção e consolidação de uma avaliação da aprendizagem na educação infantil, na perspectiva da garantia dos direitos fundamentais das crianças.

As situações identificadas nesse estudo corroboram com a ideia de que, embora existam princípios orientadores e norteadores da avaliação da aprendizagem na educação infantil, eles ainda não se traduziram em orientações de grande parte de Conselheiros, Secretarias Municipais de Educação, nem na prática das instituições de educação infantil no universo estudado, demandando maior explicitação desses 
princípios pelos órgãos federais e formações a respeito da temática em várias instâncias. Sobre isso, vale mencionar, ainda, que grande parte dos conselheiros e dirigentes municipais escutados apontou a necessidade de parcerias e maiores informações sobre acompanhamento do desenvolvimento das crianças na educação infantil.

Em suma, podemos concluir, juntamente com Sousa (2015) que, se em educação "não se escolhe impunemente os caminhos a serem seguidos na avaliação", os dados aqui discutidos revelam que as escolhas equivocadas em relação às avaliações estão recaindo justamente sobre as crianças, interferindo no seu direito ao desenvolvimento integral na educação infantil e sua continuidade nas demais etapas educacionais.

\section{Referências}

BARRETTO, Elba Siqueira de Sá; PINTO, Regina Pahim; MARTINS, Angela Maria; DURAN, Marilia Claret Geraes. Avaliação na educação básica nos anos 90 segundo os periódicos acadêmicos. Cadernos de Pesquisa (online), 2001, n. 114, p. 49-88. Disponível em: <http://publicacoes.fcc.org.br/ojs/index.php/cp/article/view/584>. Acesso em: 15 jan. 2016.

BRASIL. Constituição da República Federativa do Brasil. Lei Federal de 05 de outubro de 1988. Disponível em:

<http://www.planalto.gov.br/ccivil_03/Constituicao/Constituicao.htm>. Acesso em: 09 mar. 2016.

BRASIL. Lei n. 9.394, de 20 de dezembro de 1996. Estabelece as diretrizes e bases da educação nacional. Diário Oficial da União, Poder Legislativo, Brasília, DF, 23 dez. 1996. Disponível em: <http://www.planalto.gov.br/ccivil_03/leis/l9394.htm>. Acesso em: 10 jan. 2016.

BRASIL. Ministério da Educação. Conselho Nacional de Educação. Parecer CNE/CEB N 20/2009. Revisão das Diretrizes Curriculares Nacionais para a Educação Infantil. Brasília. Disponível em <http://portal.mec.gov.br/index.php?option=com_docman\&view=download\&alias=2097pceb020-09\&category_slug=dezembro-2009-pdf\&/temid=30192>. Acesso em: 19 dez. 2016.

BRASIL. Ministério da Educação. Secretaria de Educação Básica. Diretrizes Curriculares Nacionais para a Educação Infantil. Brasília: MEC, SEB, 2010. 
BRASIL. Ministério da Educação. Conselho Nacional de Educação. Parecer CNE/CEB N. 17/2012. Orientações sobre a organização e o funcionamento da Educação Infantil, inclusive sobre a formação docente, em consonância com as Diretrizes Curriculares Nacionais para a Educação Infantil. Brasília, 2012. Disponível em: <http://portal.mec.gov.br/index.php?option=com_content\&id=17576\&ltemid=866>. Acesso em: 10 jan. 2015.

BRASIL. Lei n. 12.796/2013, de 4 de abril de 2013 -Altera a Lei n.9394/96, de 20 de dezembro de 1996 que estabelece as diretrizes e bases da educação nacional, para dispor sobre a formação dos profissionais da educação e dar outras providências. Diário Oficial da União, Poder Legislativo, Brasília, DF, 5 abr. 2013. Disponível em: http://www.planalto.gov.br/ccivil_03/_ato2011-2014/2013/lei/l12796.htm. Acesso em 15 dez. 2016.

BRASIL. Ministério da Educação. Secretaria de Educação Básica. Diretoria de Currículos e Educação Integral. Diretrizes Curriculares Nacionais Gerais da Educação Básica. Brasília: MEC, SEB, DICEI, 2013.

BRASIL. Plano Nacional de Educação 2014-2024: Lei n. 13.005, de 25 de junho de 2014, que aprova o Plano Nacional de Educação (PNE) e dá outras providências. Brasília: Câmara dos Deputados, edições Câmara, 2014.

CAMPOS, Maria Malta. Avaliar beneficia o aprendizado. Entrevista Nova Escola. 2012. Disponível em: <http://revistaescola.abril.com.br/politicas-publicas/entrevista-avaliarbeneficia-aprendizado703923.shtml>. Acesso em: 13 jan. 2016.

CAMPOS, Maria Malta. Avaliação na primeira infância: contribuições para o debate. In: FECOMÉRCIO CE; SESC SENAC; IPDC. Utilização de métodos e instrumentos padronizados de avaliação na primeira infância: convergências e divergências. Fortaleza: jul/2016. Disponível em: http://primeirainfancia.org.br/wpcontent/uploads/2016/08/Brochura_Avalia\%C3\%A7\%C3\%A30-na-Primeira-Inf\%C3\%A2ncia.pdf. Acesso em: 08 mar. 2018.

CIASCA, Maria Isabel Filgueiras Lima; MENDES, Débora Lúcia Lima Leite. Estudos de avaliação na educação infantil. Estudos de Avaliação Educacional, São Paulo, v. 20, n. 43, maio/ago. 2009.

DIDONET, Vital. A Avaliação na e da Educação Infantil. 2011. Disponível em: <http://www.mpsp.mp.br/portal/page/portal/Educacao/Doutrina/Avalia\%C3\%A7\%C3\%A30\%2 ona\%20Educa\%C3\%A7\%C3\%A30\%20Infantil\%20-\%20Vital\%20Didonet.doc>. Acesso em: $10 \mathrm{de}$ mar de 2016.

DIDONET, Vital. Avaliação das Políticas Públicas para a Primeira Infância. In: FECOMÉRCIO CE; SESC SENAC; IPDC. Utilização de métodos e instrumentos padronizados de avaliação na primeira infância: convergências e divergências. Fortaleza: jul./2016. Disponível em: http://primeirainfancia.org.br/wp- 
content/uploads/2016/08/Brochura_Avalia\%C3\%A7\%C3\%A30-na-Primeira-Inf\%C3\%A2ncia.pdf. Acesso em: 08 mar. 2018.

MORO, Catarina. Produção brasileira sobre avaliação em Educação Infantil: tendências. Revista Latinoamericana de Educación Infantil, v. 2, n. 2, p. 53-68, jul. 2013.

MORO, Catarina. Posicionamento sobre "Utilização/adoção de métodos e instrumentos padronizados de avaliação na primeira infância -aspectos convergentes e divergentes". In: FECOMÉRCIO CE; SESC SENAC; IPDC. Utilização de métodos e instrumentos padronizados de avaliação na primeira infância: convergências e divergências. Fortaleza: jul./2016. Disponível em: http://primeirainfancia.org.br/wpcontent/uploads/2016/08/Brochura_Avalia\%C3\%A7\%C3\%A30-na-Primeira-Inf\%C3\%A2ncia.pdf. Acesso em: 08 mar. 2018.

MORO, Catarina; SOUZA, Gizele de. Produção acadêmica brasileira sobre avaliação em educação infantil: primeiras aproximações. Estudos de Avaliação Educacional, São Paulo, v. 25, n. 58, p. 100-125, maio/ago. 2014.

NEVES, Vanessa Ferraz Almeida; MORO, Catarina. Avaliação na Educação Infantil: um debate necessário. Estudos de Avaliação Educacional, São Paulo, v. 24, n. 55, p. 12-32, abr./ago. 2013.

OLIVEIRA, João Batista Araújo. Avaliação na Educação Infantil: cui bono? In: FECOMÉRCIO CE; SESC SENAC; IPDC. Utilização de métodos e instrumentos padronizados de avaliação na primeira infância: convergências e divergências. Fortaleza: jul./2016. Disponível em: http://primeirainfancia.org.br/wpcontent/uploads/2016/08/Brochura_Avalia\%C3\%A7\%C3\%A30-na-Primeira-Inf\%C3\%A2ncia.pdf. Acesso em: 08 mar. 2018.

PAZ, Senhorinha de Jesus Pit. A avaliação na educação infantil: análise da produção acadêmica brasileira presente nas reuniões anuais da ANPEd entre 1993 e 2003. 2005. Dissertação (Mestrado) Universidade Federal de Santa Catarina, Centro de Ciências da Educação, Florianópolis. 2005.

POLTRONIERI, Heloísa; CALDERÓN, Adolfo Ignacio. Avaliação na educação básica: A Revista Estudos em avaliação educacional. Estudos Avaliação Educacional, São Paulo, v. 23, n. 53, p. 82-103, set./dez. 2012.

RIBEIRO, Bruna. A qualidade na educação infantil: uma experiência de autoavaliação em creches da cidade de São Paulo. 2010. Dissertação (Mestrado) - Pontifícia Universidade Católica de São Paulo, Faculdade de Educação, São Paulo, 2010.

RIBEIRO, Bruna. Documentação Pedagógica e o desafio de cruzar fronteiras. In: MAFRA, Jason Ferreira; BATISTA, José Carlos de Freitas; BAPTISTA, Ana Maria Haddad. Educação básica: concepções e práticas. São Paulo: BT Acadêmica, $2015^{\mathrm{a}}$. 
RIBEIRO, Bruna. Avaliação da educação infantil no Brasil: Subsídios para o debate. In: Rede Marista de Solidariedade. Avaliação "da" e "na" educação infantil: significando conceitos e práticas. Curitiba: Ed. Champagnat, Rede Marista de Solidariedade, 2015b.

RIBEIRO, Bruna. Avaliação da aprendizagem das crianças: insumos para o debate. In: DIRETORIA DE CURRÍCULOS E EDUCAÇÃO INTEGRAL. COORDENAÇÃO GERAL DE EDUCAÇÃO INFANTIL, SEB/MEC. Relatório Técnico. São Paulo, 2016. Projeto UNESCO $B R Z / 1041$.

ROSEMBERG, Fúlvia. Políticas de Educação infantil e avaliação. Cadernos de Pesquisa, São Paulo, v. 43 n. 148, jan./abr. 2013.

SÃO PAULO (SP). SECRETARIA MUNICIPAL DE EDUCAÇÃO. DIRETORIA DE ORIENTAÇÃO TÉCNICA. Orientação Normativa $\mathbf{n}^{\circ}$ 01: avaliação na educação infantil: aprimorando os olhares- Secretaria Municipal de Educação- São Paulo: SME/DOT, 2014.

MACEIO. SECRETARIA MUNICIPAL DE EDUCAÇÃO. Documentação e avaliação. In: MACEIO. SECRETARIA MUNICIPAL DE EDUCAÇÃO. Orientações curriculares para a educação infantil da rede municipal de Maceió. Maceió: EDUFAL, p. 177-189, 2015.

SOUSA, Sandra Zákia. Avaliação da Educação Infantil: propostas em debate no Brasil. Interacções, n. 32 v. 10, p. 68-88, 2014.

SOUSA, Sandra Zákia. Transcrição da palestra proferida no Seminário Nacional Currículo e Avaliação da Educação Infantil: politicas para a primeira infância. 2015. Disponível em: <https://youtu.be/PQ2tbHrvD20>. Acesso em: 05 jan. 2016.

SOUSA, Sandra Zákia; PIMENTA, Cláudia. Oliveira. Avaliação da educação infantil: aportes de iniciativas estrangeiras. Estudos de Avaliação Educacional, São Paulo, v. 27, n. 65, p. 376-406, maio/ago. 2016.

Universidade do Estado de Santa Catarina - UDESC Programa de Pós-Graduação em Educação - PPGE 